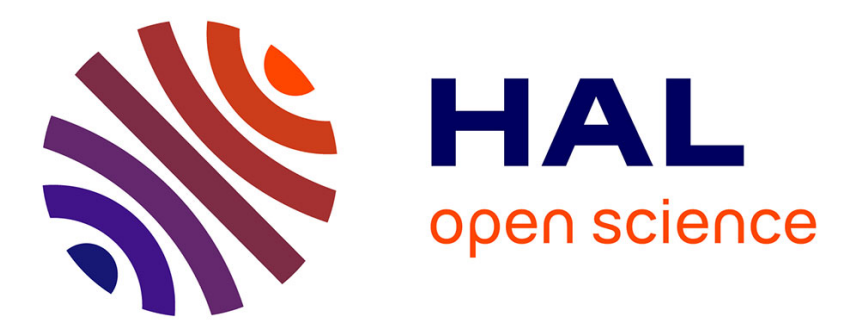

\title{
Aligned carbon nanotubes catalytically grown on iron-based nanoparticles obtained by laser-induced CVD
}

Francois Le Normand, Costel Sorin Cojocaru, Ovidiu Ersen, Pierre

Legagneux, Laurent Gangloff, C. Fleaca, Rodica Alexandrescu, Florin

Dumitrache, Ion Morjan

\section{To cite this version:}

Francois Le Normand, Costel Sorin Cojocaru, Ovidiu Ersen, Pierre Legagneux, Laurent Gangloff, et al.. Aligned carbon nanotubes catalytically grown on iron-based nanoparticles obtained by laserinduced CVD. Applied Surface Science, 2007, 254, pp.1058-1066. 10.1016/J.APSUSC.2007.08.054 . hal-00541137

\section{HAL Id: hal-00541137 \\ https://hal.science/hal-00541137}

Submitted on 2 Mar 2013

HAL is a multi-disciplinary open access archive for the deposit and dissemination of scientific research documents, whether they are published or not. The documents may come from teaching and research institutions in France or abroad, or from public or private research centers.
L'archive ouverte pluridisciplinaire HAL, est destinée au dépôt et à la diffusion de documents scientifiques de niveau recherche, publiés ou non, émanant des établissements d'enseignement et de recherche français ou étrangers, des laboratoires publics ou privés. 


\title{
Applied Surface Science \\ 254 (2007) 1058-1066 \\ DOI: http://dx.doi.org/10.1016/j.apsusc.2007.08.054
}

\section{Aligned carbon nanotubes catalytically grown on iron-based nanoparticles obtained by laser-induced CVD}

\author{
F. Le Normand ${ }^{\mathrm{a}, *}$, C.S. Cojocaru ${ }^{\mathrm{a}, 1}$, O. Ersen ${ }^{\mathrm{a}}$, P. Legagneux ${ }^{\mathrm{b}}$, \\ L. Gangloff ${ }^{\mathrm{b}}$, C. Fleaca ${ }^{\mathrm{a}, \mathrm{c}}$, R. Alexandrescu ${ }^{\mathrm{c}}, \mathrm{F}$. Dumitrache ${ }^{\mathrm{c}}$, I. Morjan ${ }^{\mathrm{c}}$ \\ ${ }^{a}$ Groupe Surfaces and Interfaces, IPCMS, UMR 7504 CNRS, Bat 70, 23 rue du Loess, 67034 Strasbourg Cedex, France \\ ${ }^{\mathrm{b}}$ THALES R\&T, Départementale 128, 91747 Palaiseau Cedex, France \\ ${ }^{c}$ National Institute for Lasers, Plasma and Radiation Physics, Laser Department, P.O. Box MG-36, R-76900 Bucharest, Romania \\ ${ }^{1}$ Present address: Laboratoire de Physique des Interfaces et des Couches \\ Minces (LPICM), École Polytechnique, UMR 7647 CNRS, Route de Saclay, \\ 91128 Palaiseau Cedex, France.
}

\begin{abstract}
Iron-based nanoparticles are prepared by a laser-induced chemical vapor deposition (CVD) process. They are characterized as body-centered Fe and $\mathrm{Fe}_{2} \mathrm{O}_{3}$ (maghemite/magnetite) particles with sizes ::;5 and $10 \mathrm{~nm}$, respectively. The Fe particles are embedded in a protective carbon matrix. Both kind of particles are dispersed by spin-coating on $\mathrm{SiO}_{2} / \mathrm{Si}\left(\begin{array}{ll}1 & 0\end{array}\right)$ flat substrates. They are used as catalyst to grow carbon nanotubes by a plasma- and filaments-assisted catalytic CVD process (PE-HF-CCVD). Vertically oriented and thin carbon nanotubes (CNTs) were grown with few differences between the two samples, except the diameter in relation to the initial size of the iron particles, and the density. The electron field emission of these samples exhibit quite interesting behavior with a low turn-on voltage at around $1 \mathrm{~V} / \mathrm{mm}$.
\end{abstract}

\section{Introduction}

Carbon nanotubes (CNTs) are produced by many techniques since their first experimental evidence by Iijima [1]. Differences occur between CNTs according to their preparation mode. By high temperature preparation techniques such as arc discharge or laser ablation, powders are obtained. By low temperature preparation techniques such as pyrolysis or chemical vapor deposition (CVD) methods, films may be grown [2]. In these later techniques, the use of transition metal particles (TMP = Fe, Co, $\mathrm{Ni}$, etc.) as catalyst is required (Catalytic CVD or CCVD) to grow CNTs. In order to take benefit of the attractive electron field emission properties, films of vertically aligned CNTs must be grown. The most pertinent way to achieve this is to introduce an electric field normal to the surface. Thus, the assistance of plasma during the growth (plasma-enhanced CCVD or PE CCVD process) is now widely developed [3]. Plasma activation includes either direct current, or microwave or radiofrequency waves. In addition, the preparation of oriented CNTs requires to start from well-defined, plain surfaces and to control the selectivity in carbon, the geometry (aspect ratio), the density of CNTs and the electrical conductivity at the interface with the substrate [4]. The density and the size of the catalytic metallic nanoparticles previously deposited onto the substrate mostly determine the subsequent CNTs density and size [5]. Now one of the main challenge in the preparation of CNTs-based devices for electron field emission is to address catalytic particle of controlled size at a controlled location. Insofar many preparation and dispersion techniques of the catalytic nanoparticles have been described in the literature, including printing [6], electrochemical deposition [7], sputtering [8] and evaporation methods [9]. The main conclusions are: (i) very small particles (size ca. $<10 \mathrm{~nm}$ ) are difficult to spread out and to stabilize on plain surfaces; (ii) homogeneity of the particle size distribution is poor except when the deposition is controlled by lithographic top-down processes and (iii) density is difficult to control, especially low densities are required to suppress the screening effects of adjacent CNTs emitters in electron field emission. This last point is crucial to get an optimized enhancement of the electric field at the top of the CNT emitter. Recently the preparation of small iron oxide [10] 

and $\mathrm{Fe}-\mathrm{C}$ [11] nanocomposite particles with homogeneous sizes around $5 \mathrm{~nm}$ were described. They were prepared by a $\mathrm{CO}_{2}$ laserassisted CVD process, usually called the laser pyrolysis of gas phase reactants. The synthesis proceeds via the ethylenesensitized IR laser-induced iron pentacarbonyl decomposition. We describe in this paper the catalyst preparation, the CNT growth and the field emission results obtained with vertically aligned CNTs grown from such small particles spread out on a flat $\mathrm{SiO}_{2} / \mathrm{Si}\left(\begin{array}{lll}1 & 0 & 0\end{array}\right)$ surface.

\section{Experimental}

\subsection{Preparation of iron-based powders}

The iron-based nanopowders were obtained in a flow reactor, by the IR laser irradiation of iron pentacarbonyl-based gas mixtures. The experimental apparatus was presented in details elsewhere [12,13]. Briefly, the focused continuous-wave (CW) $\mathrm{CO}_{2}$ laser radiation was orthogonally crossed with the reactant gas stream that was admitted to the centre of the reaction cell through a nozzle system. The reactive flow gas was confined to the flow axis by a coaxial Ar stream. The interaction of reactant gas with the laser beam resulted in a reddish-yellow flame. The nucleated particles formed during reaction were entrained by the gas stream to the cell exit where they were collected in a trap, closed with a microporous filter in the direction of the rotary pump. For producing iron-based nanoparticles, iron pentacarbonyl precursor $\mathrm{Fe}(\mathrm{CO})_{5}$ was used. Since the $\mathrm{Fe}(\mathrm{CO})_{5}$ molecule did not absorb in the $10 \mathrm{~mm}$ region, $\mathrm{C}_{2} \mathrm{H}_{4}$ or $\mathrm{SF}_{6}$ was used as sensitizer. They were excited by the absorption of the $\mathrm{CO}_{2}$ laser radiation and they transferred the absorbed energy by collision towards the other reaction partners, thus finally increasing the translation temperature of the whole system.

\subsubsection{Fe-C nanoparticles}

The FeC nanocomposites (denoted here sample FeC) were formed by small iron particles dispersed in a carbon matrix. In the first step, the iron pentacarbonyl vapor carried by an ethylene flow (150 standard cubic centimeter (sccm)) exited through the central nozzle (diameter $2.5 \mathrm{~mm}$ ) and was pyrolysed by the laser beam ( $80 \mathrm{~W}$ laser power). The freshly formed iron nanoparticles were collected by the filter. In the second step, the flow of iron pentacarbonyl was stopped and a mixture of acetylene and $\mathrm{SF}_{6}\left(\mathrm{SF}_{6}: \mathrm{C}_{2} \mathrm{H}_{2}=1: 4\right)$ was passing through the central nozzle (mixture flow rate: $250 \mathrm{sccm}$ ). The hot carbon fragments formed by the pyrolysis of acetylene were entrained toward the filter (positioned in the vicinity of the induced reaction flame) where they covered the native iron already stored in situ onto the filter.
Studies of $\mathrm{Fe}(\mathrm{CO})_{5}$ sequential decarbonylation by laser pyrolysis [11-13] revealed the fast removal of carbonyl ligands (first bond energy of $173.7 \mathrm{~kJ} / \mathrm{mol}$ ), with the formation of metallic iron and $\mathrm{CO}$ according to

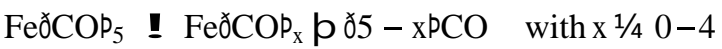

In the two-step laser pyrolysis experiment, the high reactivity of freshly formed iron nanoparticles could promote acetylene dissociation and chemisorption of hydrocarbon fragments. On the other hand, $\mathrm{SF}_{6}$ has a high absorption cross-section towards the $\mathrm{CO}_{2}$ laser radiation (absorption coefficient $\mathrm{a}=3.32 \times 10^{-1} \mathrm{~m}^{-1} \mathrm{~Pa}^{-1}$ at the $10 \mathrm{P} 20 \mathrm{CO}_{2}$ emission line). Consequently, the use of $\mathrm{SF}_{6}$ as sensitizer in the second step of the experiment could strongly speed up hydrocarbon decomposition.

\subsubsection{FeO nanoparticles}

Iron oxide $\left(\mathrm{Fe}_{2} \mathrm{O}_{3}\right)$ particles of nanometric size (denoted here as sample $\mathrm{FeO}$ ) were obtained from $\mathrm{Fe}(\mathrm{CO})_{5} /$ air sensitized with ethylene mixtures. They were prepared in a single step process, using a triple nozzle system described elsewhere [10]. Air (as oxidizer) was flowing through the inner nozzle tube while the middle tube allowed the entrance of $\mathrm{Fe}(\mathrm{CO})_{5}$ vapor, carried by $\mathrm{C}_{2} \mathrm{H}_{4}$ sensitizer. Efficient gas heating (through collision energy transfer) and subsequent chemical-induced oxidative processes were favored by the relatively high value of the ethylene flow (see Table 1).

The different parameters for the preparation of iron-based nanoparticles by the laser pyrolysis are summarized in Table 1.

\subsection{Growth of carbon nanotubes by PE-HF-CCVD}

\subsubsection{Catalyst preparation}

A thin (8 nm thick) $\mathrm{SiO}_{2}$ layer was deposited by thermal CVD on a heavily doped $\mathrm{Si}\left(\begin{array}{lll}1 & 0 & 0\end{array}\right)$ sample (Sb n-doped with $\mathbf{r}=3 \mathrm{mV} \mathrm{cm}$ ). This oxide layer was added to prevent the silicide formation during further CNTs growth at high temperature, while ensuring electrical conduction by tunneling effect through the $\mathrm{SiO}_{2}$ layer. The $\mathrm{Fe}$ nanoparticles were dispersed into isopropylic alcohol and spin-coated on a $\mathrm{SiO}_{2} / \mathrm{Si}\left(\begin{array}{lll}1 & 0 & 0\end{array}\right)$ substrate fixed on a heated rotating disk.

\subsubsection{Growth of carbon nanotubes by PE-HF-CCVD}

The CNTs growth was performed in a bakeable stainless steel ultra high vacuum (UHV) CVD chamber with UHV base pressure lower than $10^{-7} \mathrm{~Pa}$ directly connected to a surface analyses chamber. The sample was mounted on a Mo sample holder fixed to a motion drive that allowed (i) to accurately settle the sample with regard to the filaments (at $5 \mathrm{~mm}$ ) and to

Table 1

Experimental parameters for the synthesis of iron-carbon and iron oxide nanoparticles. The nanoparticle mean size, as determined from TEM examination is also presented

\begin{tabular}{|c|c|c|c|c|c|c|c|c|c|}
\hline Sample & $\begin{array}{l}\mathrm{C}_{2} \mathrm{H}_{4} \text { flow through } \\
\mathrm{Fe}(\mathrm{CO})_{5}(\mathrm{sccm})\end{array}$ & $\begin{array}{l}\mathrm{C}_{2} \mathrm{H}_{2} \\
\text { (sccm) }\end{array}$ & $\begin{array}{l}\text { SF6 } \\
\text { (sccm) }\end{array}$ & $\begin{array}{l}\text { Air } \\
\text { (sccm) }\end{array}$ & $\begin{array}{l}\mathrm{Ar}_{\mathrm{c}} \\
(\mathrm{sccm})\end{array}$ & $\begin{array}{l}\mathrm{Ar}_{\mathrm{w}} \\
(\mathrm{sccm})\end{array}$ & $\begin{array}{l}\mathrm{P} \\
(\mathrm{hPa})\end{array}$ & $\begin{array}{l}\mathrm{P}_{\text {Laser }} \\
(\mathrm{W})\end{array}$ & $\begin{array}{l}\text { Mean size } \\
(\mathrm{nm})\end{array}$ \\
\hline $\mathrm{FeC}$ & 150 & 225 & 25 & - & 1100 & 100 & 355 & 80 & $3-5$ \\
\hline $\mathrm{FeO}$ & 400 & - & - & 170 & 1200 & 150 & 507 & 50 & $>10$ \\
\hline
\end{tabular}


the polarisation set-up and (ii) to transfer the sample to a surface analysis chamber directly connected to the preparation chamber. The gas mixture $\left(20 \% \mathrm{C}_{2} \mathrm{H}_{2}\right.$ in $\mathrm{H}_{2}$ as carrier-gas at an overall pressure of $15.2 \mathrm{hPa}$ and a flow rate of $100 \mathrm{sccm}$ ) was thermally activated by hot filaments ( $\mathrm{P}=150 \mathrm{~W}$ with filaments temperature at $2100 \mathrm{~K}$ ) and kinetic energy-activated by a primary plasma ignited by polarisation between an anode and a cathode grids above the sample (Bias $=335-400 \mathrm{~V}$ ). The potential of the filaments was continuously adjusted to the plasma potential. A second negative polarisation $(-20 \mathrm{~V})$ between the cathode and the sample allowed creating an extraction plasma. A fixed and controlled flux of ions (3 mA) that impinged the surface of the negatively biased sample was consequently created. The potential of the primary plasma exhibited a slight positive evolution throughout the deposition $(\because: 20 \mathrm{~V})$, probably due to modifications of the deposition surface with growing CNTs. More details on the experimental set up have been elsewhere described $[14,15]$.

\subsection{Sample characterizations}

\subsubsection{Surface analyses}

The surface analyses (X-ray photoelectron spectroscopy (XPS), Auger electron spectroscopy (AES) and reflective electron energy loss spectroscopy (REELS)) were carried out in a custom-built system equipped with a VSW $100 \mathrm{~mm}$ hemispherical analyzer of the kinetic energy of the electrons. The base pressure was $10^{-8} \mathrm{~Pa}$ in the chamber and $5 \times 10^{-8} \mathrm{~Pa}$ during the analyses. The X-ray source was an unmonochromatized PHI Mg anode providing photons of kinetic energy $1253.6 \mathrm{eV}$ impinging the sample with a 308 incidence angle. The acceleration voltage was $13 \mathrm{kV}$ and the power was $300 \mathrm{~W}$.
Electrons were collected in a direction normal to the surface of the substrate. The kinetic energy of the electrons was analyzed with a fixed transmission analyzer of $22 \mathrm{eV}$. This yields an overall resolution of $0.60 \mathrm{eV}$. The spectrometer was calibrated by reference to the core levels of clean copper, silver and gold foils with binding energies at 75.14, 83.98, 368.26 and $932.67 \mathrm{eV}$ for the $\mathrm{Cu} 3 \mathrm{p}, \mathrm{Au} 4 \mathrm{f}_{7 / 2}, \mathrm{Ag} 3 \mathrm{~d}_{5 / 2}$ and $\mathrm{Cu} 2 \mathrm{p}_{3 / 2}$ core levels, respectively. Other details have been elsewhere reported [14]. The electron energy for AES and REELS were 3 and $1 \mathrm{keV}$, respectively.

\subsubsection{Transmission electron microscopy (TEM) and scanning electron microscopy (SEM)}

TEM observations were performed on a TOPCON 002B microscope operating at $200 \mathrm{kV}$. The powder was dispersed into an ultrasonicated isopropylic alcohol solution. A small droplet of the solution was then dispersed on a copper grid covered with an amorphous carbon membrane. The CNT sample was scratched by a diamond tip and the residues were pulled directly on a holy membrane. SEM observations were performed on a XL30S-FEG PHILIPPS working at $3 \mathrm{kV}$.

\subsubsection{Raman spectroscopy}

Spectra were recorded on a Renishaw spectrometer using a He-Ne laser at $\mathbf{I}=632.8 \mathrm{~nm}$ equipped with a Notch filter and working in a backscattering geometry.

\subsection{Field emission measurements}

The field emission measurements were performed at THALES-R\&D (Centre de Recherches Corbeville-Orsay, France) on an UHV set up (limiting vacuum $10^{-9}$ Torr) which

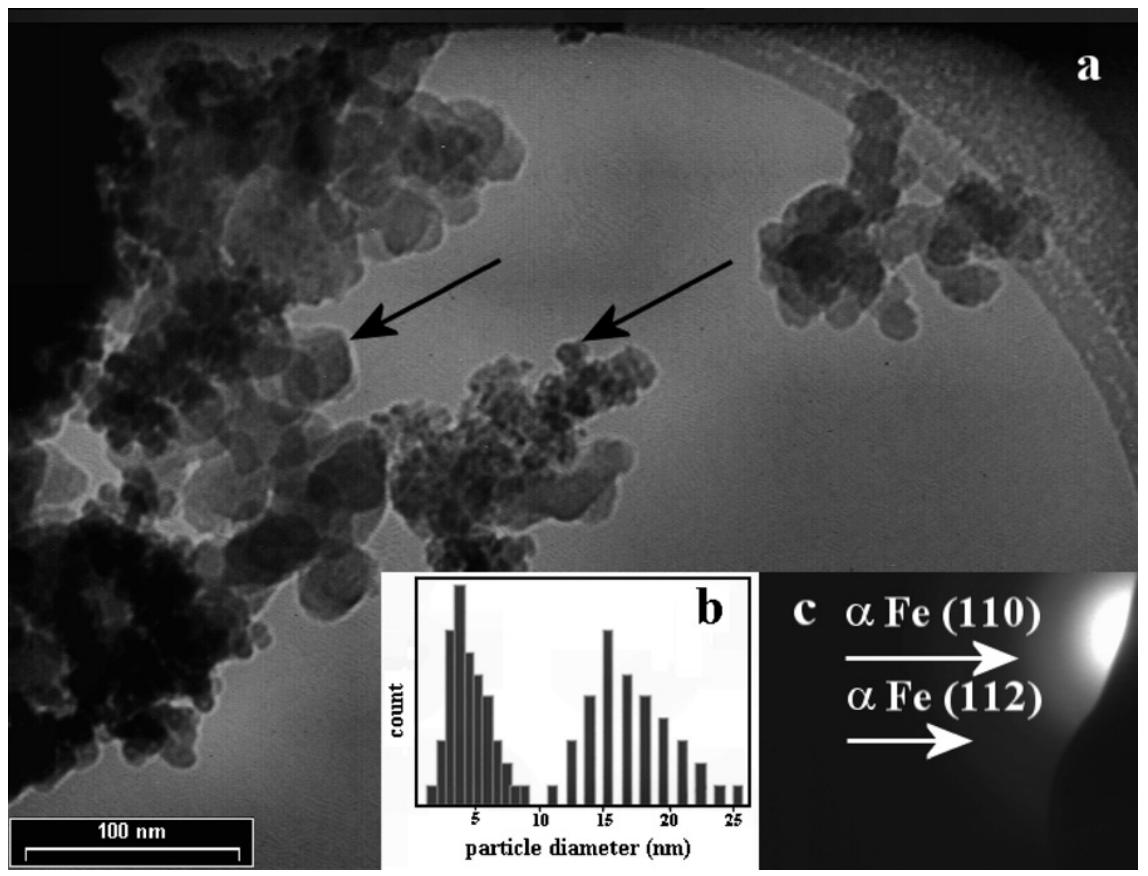

Fig. 1. (a) TEM image of carbon-iron clusters (sample labeled FeC): the inserts show (b) the SAED patterns with Fe(bcc) identification rings [13] and (c) the particle size distribution exhibiting two maxima corresponding to small iron particles and to larger particles (probably carbon), respectively, as seen in the image by arrows. 
was elsewhere reported [16]. A planar triode configuration was used, in which the sample (of maximum size $9 \mathrm{~mm} \times 9 \mathrm{~mm}$ ), was fixed in front of an extraction grid biased to the potential $\mathrm{V}$ and distant by $\mathrm{d}=110 \mathrm{~mm}$ by mean of a quartz spacer. The mean apparent electric field around the sample was then $\mathrm{E}=\mathrm{V} /$ d. The emitted electrons were collected on an ITO (indium tin oxide)/phosphorus flat anode provided with filtration grids to discriminate the secondary electrons. The emitted current $I_{a}$ was measured with a picoamperometer. To get the current density $j=I_{a} / S$, the emitting surface $S$ was estimated to $0.7 \mathrm{~mm}^{2}$, accounting for the opaqueness of the extraction grid.

The samples were conditioned by progressively increasing the extraction potential before performing a full cycle. This one was carried out by subsequently rising and dropping the extraction potential. Thus, many cycles were performed on the same sample up to a saturation of the electron emission. Stable conditions were obtained after many of these cycles and only the results of the steady field emission properties of the sample were reported. The emission onset was defined as the field from which an emission could be detected, which presently meant an emission density above $0.1 \mathrm{nA} / \mathrm{cm}^{2}$.

\section{Results and discussion}

\subsection{Fe-based nanoparticles prepared by laser pyrolysis}

The TEM examination of the FeC samples suggests that the formation of iron nanoparticles occurs rather independently from carbon nucleation. The image in Fig. 1a indicates a complex morphology of the powder with different particle
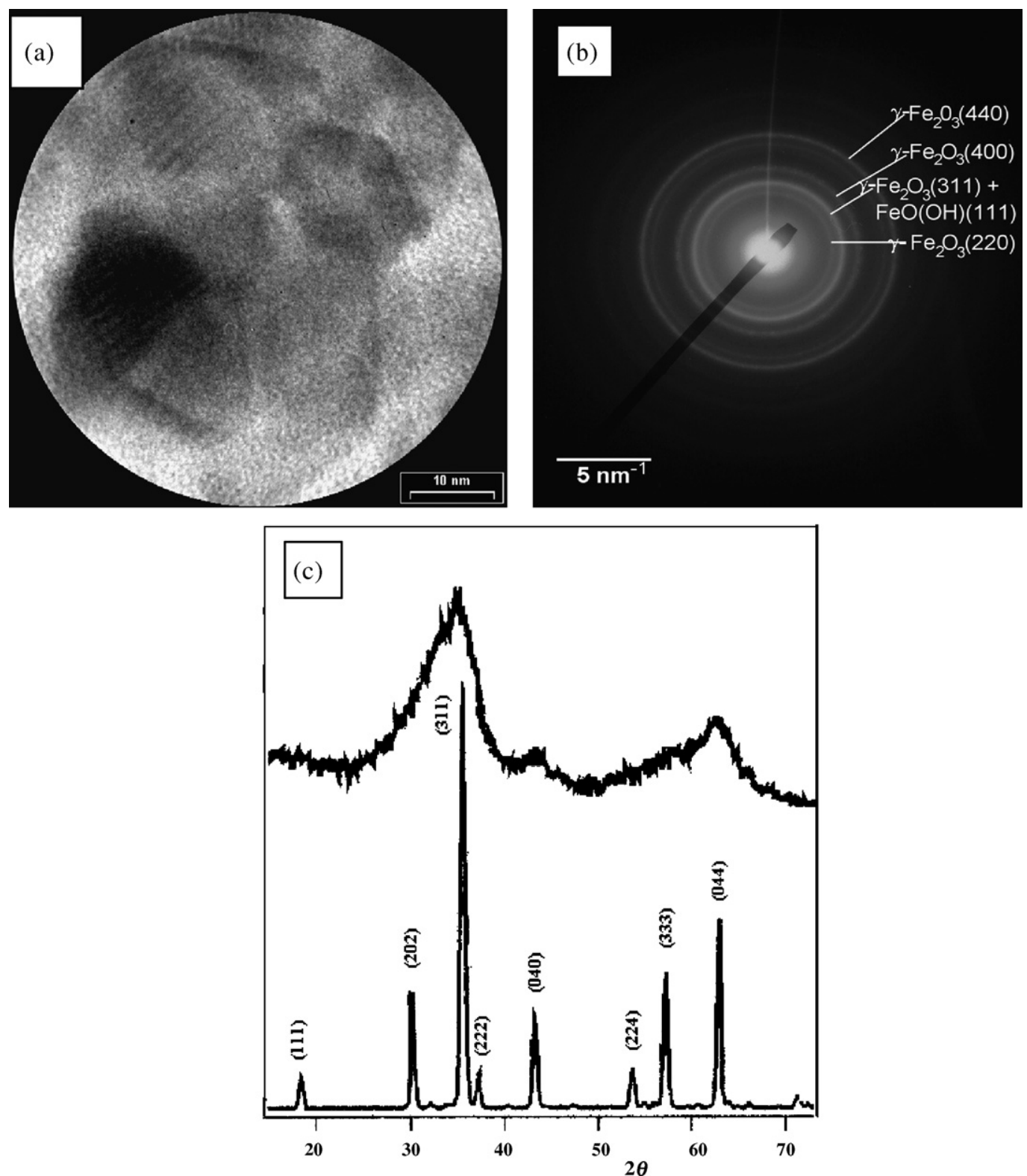

Fig. 2. (a) TEM image of iron cluster (sample labeled FeO); (b) selected area diffraction and (c) X-ray diffraction showing the characteristic (3 11 ), (0 40 ) and (0 4 4) diffraction peaks of $\mathrm{FeO}$ nanoparticles in good agreement with the diffraction patterns of the g- $\mathrm{Fe}_{2} \mathrm{O}_{3} / \mathrm{Fe}_{3} \mathrm{O}_{4}$ oxide phases (see text). 
dimensions. The presence of small particles (about $5 \mathrm{~nm}$ mean diameter) as well as large ones (about $16 \mathrm{~nm}$ mean diameter) may be distinguished. The particle size distribution (PSD) performed on this selected area (see insert b in Fig. 1) confirms the existence of the two aforementionned maxima, corresponding to the small and to the large particles, respectively. The PSD was obtained by counting the particles of different sizes in the electron microscope image. One should mention that a bimodal log-normal distribution (not presented here) is a good fit for the particles represented in Fig. 1a. According to the selected area electron diffraction (SAED) analysis (Fig. 1c), the rings can be associated with the body-centered cubic phase of iron (a-Fe) [17]. They are attributed to diffractions from the small particles. The TEM observations suggest an amorphous character for the large particles, which are probably made up of amorphous carbon.

TEM images on FeO sample show well facetted-particles of size $10 \mathrm{~nm}$ with roughly facetted morphology (Fig. 2a). SAED patterns (Fig. 2b) on a collection of particles point to the major presence of maghemite/magnetite phases $\left(g-\mathrm{Fe}_{2} \mathrm{O}_{3} /\right.$ $\left.\mathrm{Fe}_{3} \mathrm{O}_{4}\right)$ [18]. It is known that it is difficult to distinguish between these two iron oxide phases from diffraction patterns alone. Possibly some patterns corresponding to goethite $\mathrm{FeO}(\mathrm{OH})$ are also present [19].

The X-ray patterns of FeO sample (Fig. 2c) exhibit rather broad peaks which could be assigned to a maghemite/magnetite iron phase, accordingly Miller indexed in a cubic system. Due to the broadness of the spectrum (the experimental curve is superposed to the calculated $\mathrm{g}-\mathrm{Fe}_{2} \mathrm{O}_{3}$ phase) which is usually associated with the formation of very small particles in the nanometer range, the possible contributions from amorphous components or phase impurities (such as carbon traces) cannot be excluded. However, the amount of carbon fragments should be very small since the SAED powder characterization did not clearly reveal its presence in $\mathrm{FeO}$ samples.

\subsection{CNTs growth catalyzed by Fe-based nanoparticles}

Fig. 3 displays typical SEM images of the CNTs film grown from $\mathrm{FeC}$ (Fig. 3a) and $\mathrm{FeO}$ (Fig. 3b) samples, respectively, on areas partially covered with iron-based nanoparticles (namely CNTs@FeC and CNTs@FeO samples). Both samples clearly exhibit nanotubes with a preferential orientation normal to the surface. However, the two samples display some differences in morphology: the distribution of tubes is quite homogeneous with a narrow size distribution on CNTs@FeO sample around $20 \mathrm{~nm}$, whereas the tubes on CNTs@FeC sample are thinner and rather agglomerated in bundles. These different sizes of the CNTs can be directly correlated to the size of the catalytic nanoparticles in the initial powders, with a ratio (size of the catalyst/size of the CNT) which is around 2. An examination with a higher magnitude (not shown) reveals however that these tubes have generally many defects resulting in a poor alignment. These defects lead to agglomeration of the tubes at the top of the film in CNTs@FeC sample. Although many defects are also present, the nanotubes do not display such agglomeration on the CNTs@FeO samples. This can be
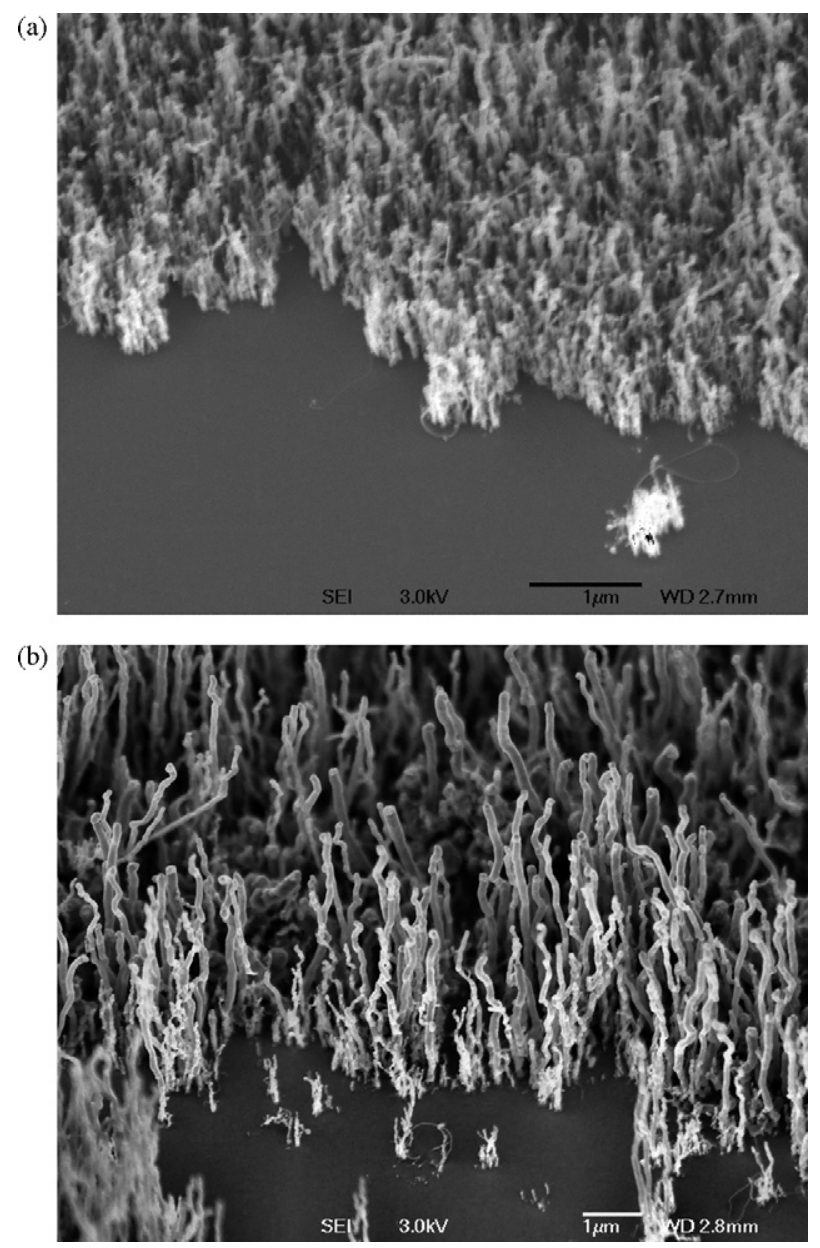

Fig. 3. SEM images of the CNTs growth on (a) FeC sample; (b) FeO sample.

attributed to their lower density. From highly contrasted SEM images (not shown), it can be stated that many of the metallic particles are located on top of the growing particle, giving some consistency to the so-called top growth mechanism. A clear film-termination can be observed on the CNTs@FeO sample, whereas the top of the film is partly covered with an amorphous deposit on the CNTs@FeC sample. The origin of this difference will not be discussed here. TEM images of Fig. 4A confirm the selective formation of nanotubes in both samples with narrow diameter distributions in the range $10-20 \mathrm{~nm}$, a bamboo-like organization of the hollowed part of the nanotubes and a metallic particles at their ends. These faceted particles are anisotropic, displaying the large axis in the growth direction of the tube. Some deep incorporation of metal inside the tubes can also be observed. The diffraction on one single nanotube displays the arcs characteristic of oriented graphite (Fig. 4C). The diffraction on a collection of nanotubes (Fig. 4B) reveals again the annular patterns of graphite corresponding to nanotubes as well as many individual spots. The brighter spots

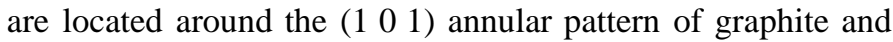
might correspond to the martensite $\mathrm{g} F(\mathrm{C})$ (1 0101$)$ or the cementite $\mathrm{Fe}_{3} \mathrm{C}\left(\begin{array}{lll}1 & 0 & 2\end{array}\right)$ or $\left(\begin{array}{lll}2 & 3 & 0\end{array}\right)$. Others spots can be assigned

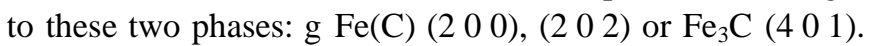

The Fe coverage after carbon nanotubes growth, estimated from the XPS Fe 2p intensity, is much larger on the CNTs@FeC 
(A)

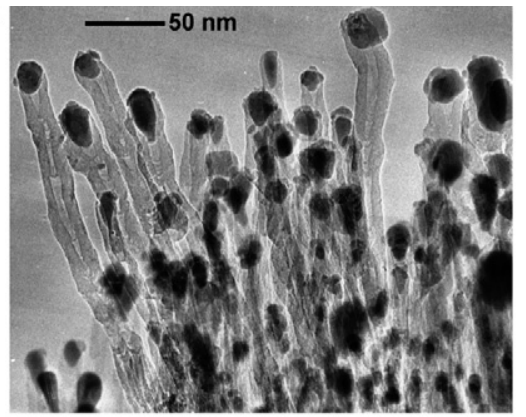

(B)
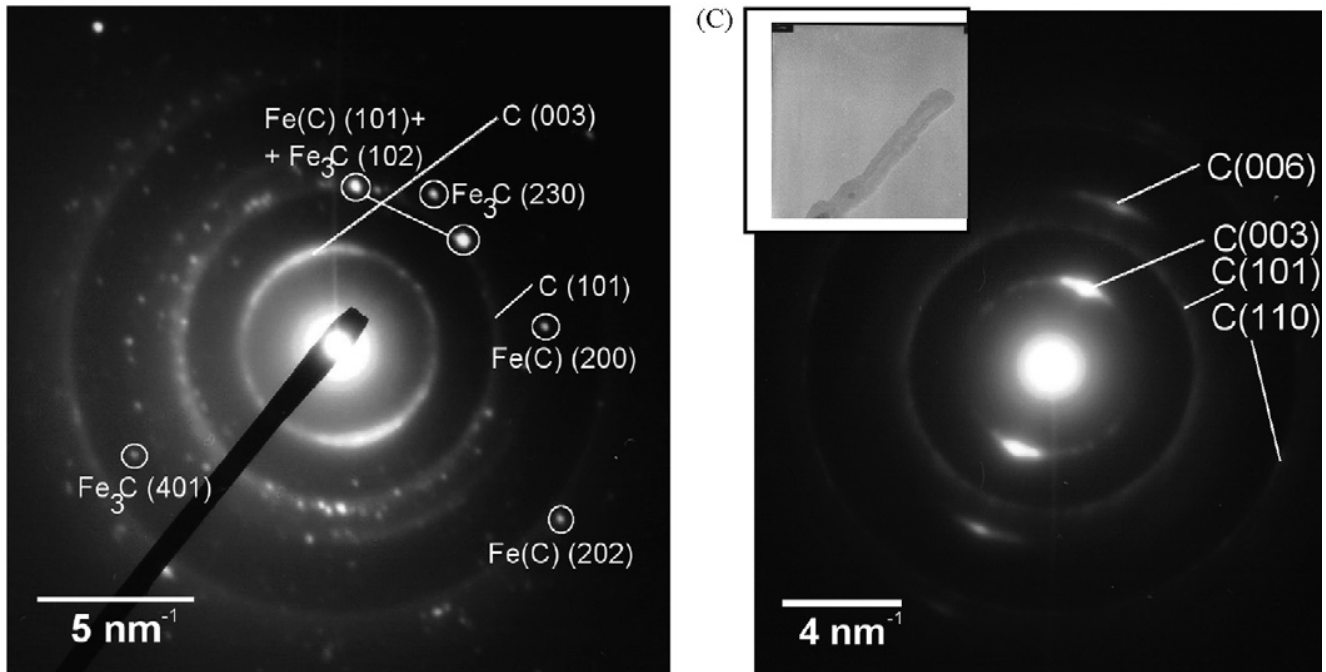

Fig. 4. TEM images of CNTs on (A) sample FeC; (B) the SAED patterns on image (A) and (C) diffraction patterns on one single nanotube exhibited in insert.

sample than on the CNTs@FeO sample (Fig. 5). This is in good agreement to the larger density observed by SEM on CNTs@FeC sample (Table 2). The Fe 2p spectra (insert of Fig. 5) displays a narrow Fe 2 $\mathrm{p}_{3 / 2}$ line around $707.5 \mathrm{eV}$, with a slight difference between CNTs@FeO sample (707.35 eV) and CNTs@FeC sample(707.85 eV). This energy range is however

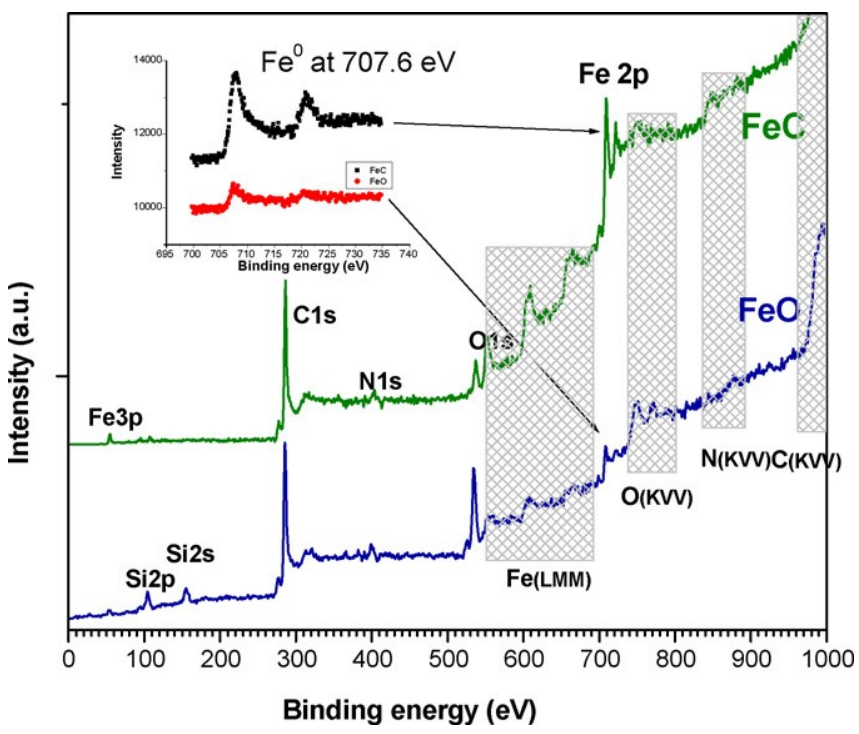

Fig. 5. XPS wide spectra on FeC and FeO samples, respectively. The insert displays the XPS Fe 2p core levels of $\mathrm{FeC}$ and FeO samples, respectively. characteristic of metallic iron instead of iron oxides [20]. Nevertheless it could be stated that, within the limited resolution of the apparatus and the low iron concentration, it is not possible to accurately distinguish metallic iron from some other carbidic iron phases [21]. The nature of the carbon phase has been further studied by AES of the C KVV Auger transition (Fig. 6) and by electron loss spectroscopy in the reflection mode (REELS) (Fig. 7). Auger and REELS spectra are displayed both in the derived $\mathrm{dN}(\mathrm{E}) / \mathrm{dE}$ mode and the $\mathrm{N}(\mathrm{E})$ mode, respectively (bottom), and the second derived (up) $\mathrm{d}^{2} \mathrm{~N}(\mathrm{E}) / \mathrm{dE}^{2}$ modes, to ascertain the main features. In addition the AES and REELS spectra of HOPG graphite recorded in the same conditions are displayed (Figs. 6C and 7C, respectively). The noticeable feature $\mathrm{A}_{0}^{0}$ at $277 \mathrm{eV}$ which occurs as a tail of the main derived transition is attributed to an Auger $\mathrm{KV}_{0} \mathrm{~V}_{0}$ transition involving the $\mathrm{p}$ electrons of the valence band. In addition to this main transition $\mathrm{KV}_{0} \mathrm{~V}_{0}$ at $262.6 \mathrm{eV}(263.8 \mathrm{eV})$ for CNTs@FeC (CNTs@FeO), respectively, other Auger transitions $\mathrm{KV}_{1} \mathrm{~V}_{1}$ at $259.3 \mathrm{eV}(258.0 \mathrm{eV})$ and $\mathrm{KV}_{2} \mathrm{~V}_{2}$ at $248.9 \mathrm{eV}(248.5 \mathrm{eV})$ are also characteristics of graphite whereas the feature occurring at $235.8 \mathrm{eV}(236.0 \mathrm{eV})$ is due to a plasmon loss. Two factors were defined elsewhere [22] with regard to graphitization, namely $\mathrm{I}^{\delta} \mathrm{A}_{0}^{0} \mathrm{p}=\mathrm{I} \delta \mathrm{P}_{0} \mathrm{p}$, the ratio of the intensity of the $A_{0}^{v}$ transition to the intensity at the main minimum $\mathrm{P}_{0}$, and $\mathrm{D}$ ð $\mathrm{P}_{0}-\mathrm{A}_{0}^{0} \mathrm{p}$ the energy difference of the same features. We note that $\mathrm{P}_{0}$ and $\mathrm{D} ð \mathrm{P}_{0}-\mathrm{A}_{0}^{v} \mathrm{p}$ are closer to HOPG graphite on CNTs@FeO sample (Table 3). Some differences 
Table 2

Growth parameters and electron field emission properties on CNTs@Fe-C and CNTs@FeO samples

\begin{tabular}{llll}
\hline Sample & Growth & & \\
\cline { 2 - 3 } & $\begin{array}{l}\text { Density } \\
\left(\times 10^{10} \mathrm{~cm}^{-2}\right)\end{array}$ & $\begin{array}{l}\text { Mean size } \\
(\mathrm{nm})\end{array}$ & $\begin{array}{l}\text { Emission threshold } \\
(\mathrm{V} / \mathrm{mm})\end{array}$ \\
\hline $\mathrm{FeC}$ & 20 & $10-15$ & 1.5 \\
$\mathrm{FeO}$ & 0.2 & $15-20$ & 1.5 \\
\hline
\end{tabular}

are noted, however, especially the shoulder between the $\mathrm{KV}_{1} \mathrm{~V}_{1}$ and $\mathrm{KV}_{2} \mathrm{~V}_{2}$ transitions which is characteristic of the occurrence of carbon nanotubes [23]. A p I p* interband transition at $6.5 \mathrm{eV}$ in the REELS spectrum (Fig. 7C) is also a clear indication of the presence of $\mathrm{sp}^{2}$ carbon, whereas the main contribution is assigned to the bulk plasmon $\varpi_{\text {ь }}$ (Table 3). We note however that the intensity of the $\mathrm{p} ! \mathrm{p}^{*}$ interband transition is rather low particularly on CNTs@FeC sample. In conclusion the investigations with AES and REELS are mostly stated a graphitic $\mathrm{sp}^{2}$ configuration.
Table 3

Main C KVV Auger and REELS characteristics on CNTs@FeC and CNTs@FeC samples

\begin{tabular}{|c|c|c|c|}
\hline Samples & CNTs@FeC & CNTs@FeO & HOPG basal \\
\hline$P_{0}(e V)$ & 267.7 & 269.5 & 270.0 \\
\hline $\mathrm{I}^{ð} \mathrm{~A}_{0}^{0} \mathrm{p}=\mathrm{I}^{ð} \mathrm{P}_{0} \mathrm{p}$ & 0.70 & 0.70 & 0.82 \\
\hline $\mathrm{D} ð \mathrm{P}_{0}-\mathrm{A}_{0}^{0} \mathrm{p}$ eVP & 3.4 & 4.7 & 4.6 \\
\hline $\mathrm{p} \unrhd \mathrm{p}^{*}(\mathrm{eV})$ & 5.8 & 6.6 & 6.5 \\
\hline $\boldsymbol{\varpi}_{\mathrm{b}}(\mathrm{eV})$ & 26.5 & 27 & 27 \\
\hline
\end{tabular}
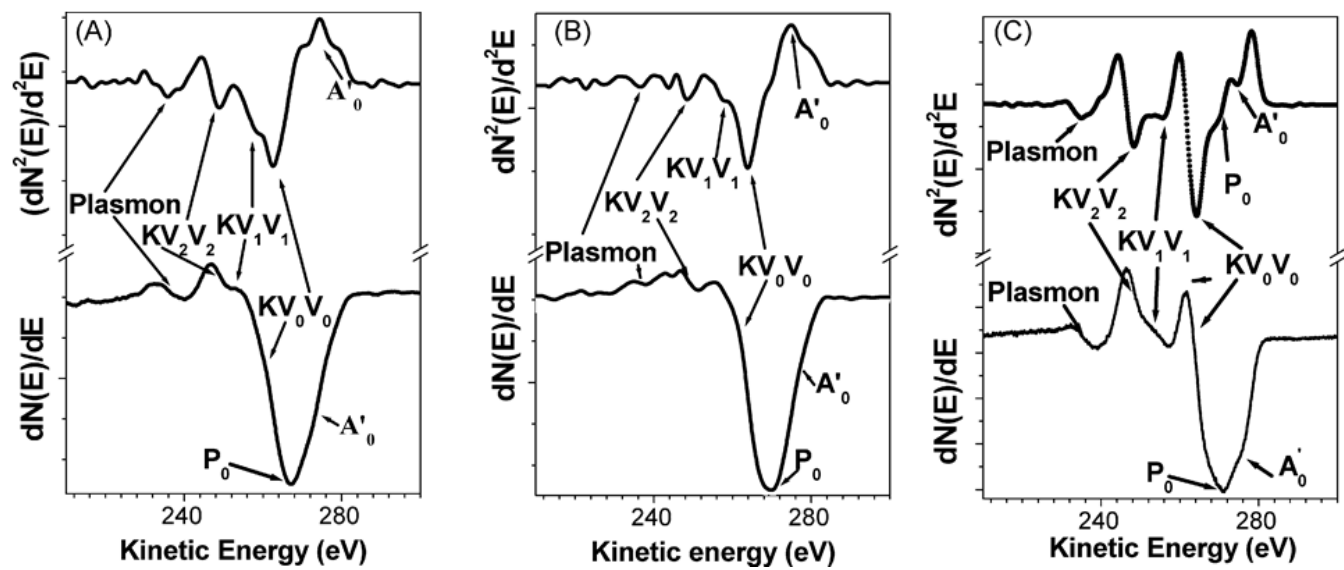

Fig. 6. AES C KVV spectra on (A) FeC; (B) FeO samples and (C) HOPG graphite, respectively. The bottom spectra are recorded in the dN(E)/dE mode. Above, the negative minima of the second derived curve $\left[\mathrm{dN}^{2}(\mathrm{E}) / \mathrm{dE}^{2}\right]$ point the main Auger transitions $\mathrm{KV}_{0} \mathrm{~V}_{0}, \mathrm{KV}_{1} \mathrm{~V}_{1}$ and $K V_{2} \mathrm{~V}_{2}$, respectively.
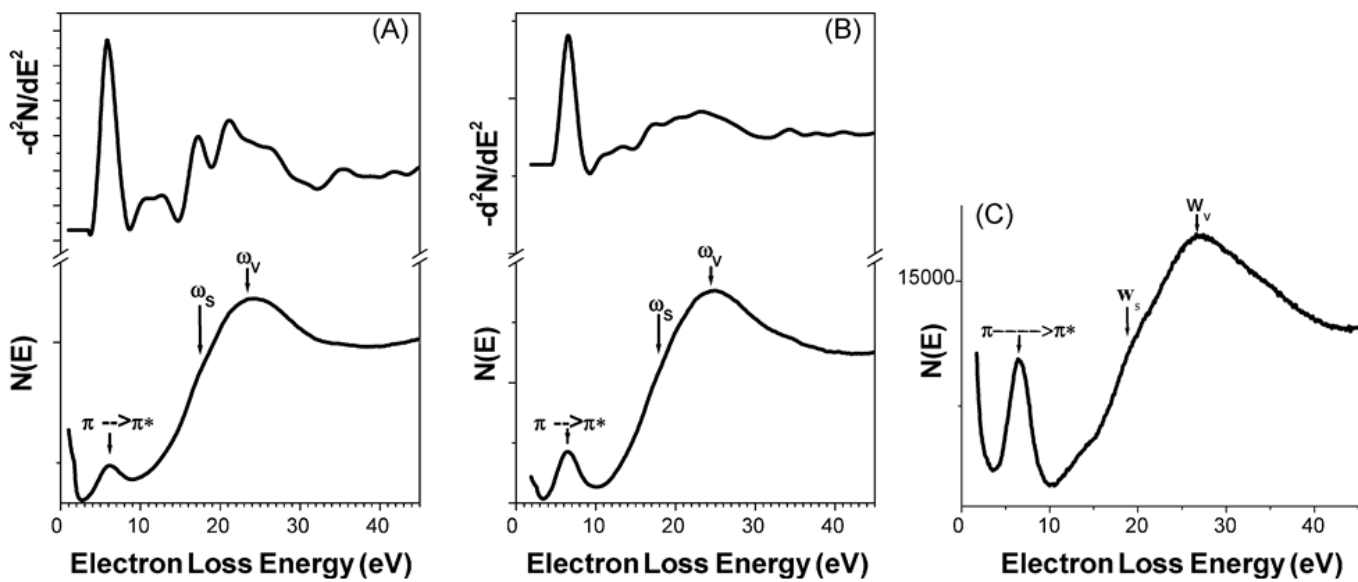

Fig. 7. REELS spectra on (A) FeC; (B) FeO samples and (C) HOPG graphite, respectively. The bottom spectra are recorded in the N(E) mode. Above, the positive minima of the second derived curve $-\left[\mathrm{dN}^{2}(\mathrm{E}) / \mathrm{dE}^{2}\right]$ point the main surface and bulk plasmons, $\mathrm{v}_{\mathrm{s}}$ and $\mathbf{v}_{\mathrm{b}}$, respectively. 


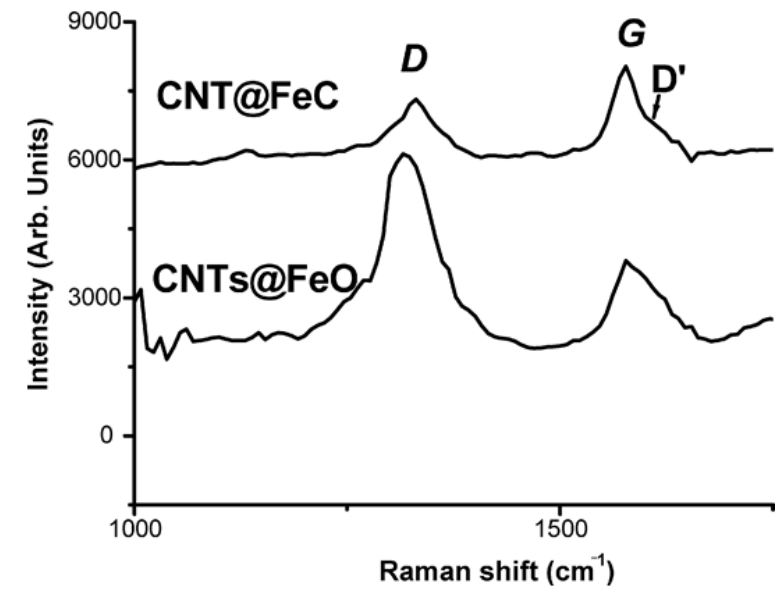

Fig. 8. Raman spectra of $\mathrm{FeC}$ and $\mathrm{FeO}$ samples.

The Raman spectra (Fig. 8) exhibit rather sharp D and G bands. The $\mathrm{D}$ band is characteristic of vibration modes on defective graphite, due to defects or size effects. A weak D band is observed on $\mathrm{FeC}$ sample with a full width at half maximum (FWHM) around $60 \mathrm{~cm}^{-1}$. This weak $\mathrm{D}$ band is an indication of fewer defects within the nanotubes. In contrast to CNTs@FeC sample, the CNTs@FeO sample shows a larger intensity as well as a larger FWHM $\left(100 \mathrm{~cm}^{-1}\right)$ of the defective band D. This is agreement with SEM observations (Fig. 3b). The main G band at $1591 \mathrm{~cm}^{-1}$ is in good agreement with the values reported in the literature for multiwall CNTs, considering the low size of the tube and the high curvature of the graphitic shells $\left(E_{k \mathrm{l}}\right)$. The sharp and narrow $G$ band at $1590 \mathrm{~cm}^{-1}$ has two weak substructures on each side at 1555 and $1600 \mathrm{~cm}^{-1}$, respectively. The substructure $\mathrm{D}^{0}$ at $1606 \mathrm{~cm}^{-1}$ can be attributed to a breakdown of the selection rules $(q=0)$ due to the curvature of the tubes that activates a $\mathrm{E}_{2 \mathrm{~g}}^{0}$ mode.

\subsection{Field emission properties}

The two samples display quite similar electron field emission (FE) curves. They start to emit at low turn-on fields

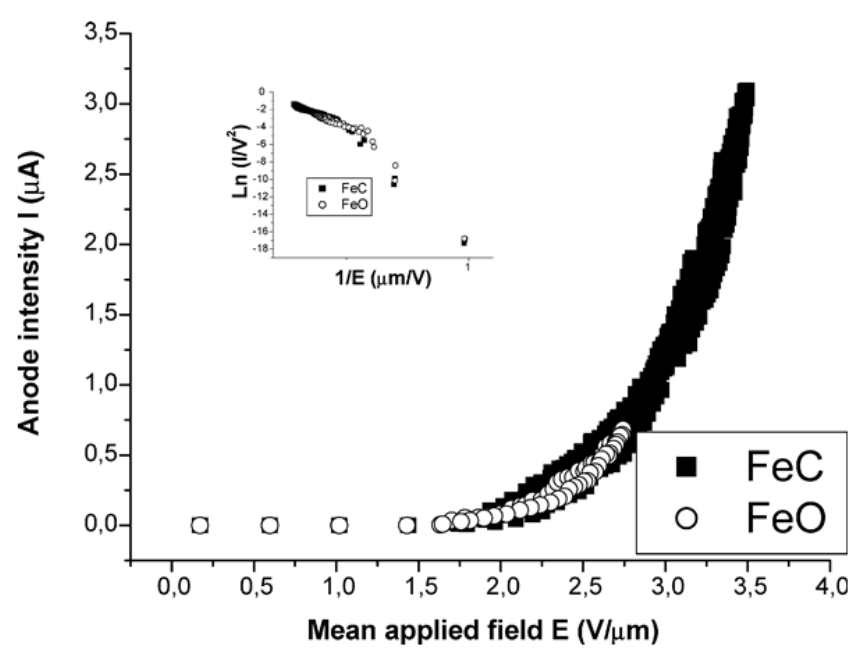

Fig. 9. I-V electron emission curves on $\mathrm{FeC}$ and $\mathrm{FeO}$ samples. In the insert the Fowler-Nordheim plot are depicted. around $1 \mathrm{~V} / \mathrm{mm}$ (Fig. 9). The Fowler-Nordheim plots display in both cases a linear behavior above $2 \mathrm{~V} / \mathrm{mm}$ with $\mathrm{b}$ values around 500 (insert of Fig. 9). The maximum of emission densities are $440 \mathrm{~mA} / \mathrm{cm}^{2}$ at $3.5 \mathrm{~V} / \mathrm{mm}$ and $100 \mathrm{~mA} / \mathrm{cm}^{2}$ at 2.6 V/mm on CNTs@FeC and CNTs@FeO samples, respectively. Moreover, the emission observed on sample CNTs@FeC is found very reproducible from one cycle to another. The difference in the intensity of the electron field emission may be attributed to the difference in density by two orders of magnitude between the two samples (Table 2). Considering the differences reported in the nature and the morphology of the CNTs@FeC and CNTs@FeO samples, the rather identical electron emission turn-on field confirms that FE is a robust property of CNT, rather insensitive to the accurate morphology of the nanotubes. This could be explained if we bear in mind that the electron emission current is not governed by electron transport along the CNT, but rather by transport at the interface with the substrate [9].

\section{Conclusion}

Small nanometric iron-based particles obtained by laserinduced pyrolysis have been prepared. They were identified as a-(bcc)Fe and $\mathrm{FeO}$ (maghemite/magnetite), respectively, by TEM, SAED and XRD. Nanoparticles size was found $:: 5$ and $10 \mathrm{~nm}$, respectively. Such particles were spread by a spincoating process in order to grow carbon nanotubes by a plasmaassisted and filaments-activated CCVD process. Vertically oriented and thin carbon nanotubes were grown. Differences between the two samples are observed in morphology and quality of nanotubes as ascertained by SEM, TEM, XPS AES and Raman spectroscopy. The electron field emission of these samples exhibits low turn-on voltages at $1 \mathrm{~V} / \mathrm{mm}$ with two emission regimes due to some inhomogeneous length distribution, and different saturation current due to the high density of emitters. However it is expected to increase the field emission properties, with the dispersion on structured substrates in order to control the density of emitters. Further works are being done in that way.

\section{References}

[1] S. Iijima, Nature 354 (1991) 56.

[2] M.S. Dresselhaus, G. Dresselhaus, P. Avouris, Carbon Nanotubes: Synthesis, Structure, Properties and Applications, Springer, Berlin, 2001, p. 29.

[3] A.V. Melechko, V.I. Merkulov, T.E. MacKnight, M.A. Guillorn, K.L. Klein, D.H. Lowndes, M.L. Simpson, J. Appl. Phys. 97 (2005) 041301.

[4] J.M. Bonard, H. Kind, T. Stockli, L.-O. Nilsson, Solid State Electronics 45 (2001) 893.

[5] M. Chhowalla, K.B.K. Teo, C. Ducati, N.L. Rupesinghe, G.A.J. Amaratunga, A.C. Ferrari, D. Roy, J. Robertson, W.I. Milne, J. Appl. Phys. 90 (2001) 5308.

[6] O. Groning, O.M. Kuttel, C. Emmenegger, P. Groning, L. Schlapbach, J. Vac. Sci. Technol. B 18 (2000) 665.

[7] P.L. Chen, J.K. Chang, C.T. Kuo, F.M. Pan, Appl. Phys. Lett. 86 (2005) 123111.

[8] K.H. Park, S. Choi, K.M. Lee, S. Lee, J. Vac. Sci. Technol. B19 (2001) 958. 
[9] F. Le Normand, C.S. Cojocaru, C. Fleaca, J.Q. Li, P. Vincent, G. Pirio, L. Gangloff, Y. Nedellec, P. Legagneux, Eur. Phys. J. Appl. Phys. 38(2007) 115

[10] I. Morjan, R. Alexandrescu, I. Soare, F. Dumitrache, I. Sandu, I. Voicu, A. Crunteanu, E. Vasile, V. Ciupina, S. Martelli, Mater. Sci. Eng. C 1020 (2002) 1 .

[11] F. Dumitrache, I. Morjan, R. Alexandrescu, R.E. Morjan, I. Voicu, I. Sandu, I. Soare, M. Ploscaru, C. Fleaca, V. Ciupina, G. Prodan, B. Rand, R. Brydson, A. Woodword, Diam. Relat. Mater. 13 (2003) 362.

[12] H. Hofmeister, F. Huisken, B. Kohn, R. Alexandrescu, S. Cojocaru, A Crunteanu, I. Morjan, L. Diamandescu, Appl. Phys. A 72 (2001) 7.

[13] R. Alexandrescu, I. Morjan, F. Dumitrache, I. Voicu, I. Soare, I. Sandu, C.T. Fleaca, Solid State Phenom. 99/100 (2004) 181.

[14] C.S. Cojocaru, A. Senger, F. Le Normand, J. Nanosci. Nanotechnol. 6 (2006) 1331-1338.
[15] C.S. Cojocaru, M. Larijani, D.S. Misra, M.K. Singh, P. Veis, F. Le Normand, Diam. Relat. Mater. 13 (2004) 270.

[16] G. Pirio, P. Legagneux, D. Pribat, K.B.K. Teo, M. Chhowalla, G.A.J. Amaratunga, W.I. Milne, Nanotechnology 13 (2002) 1.

[17] ASTM file no. 85-1410.

[18] ASTM file no. 39-1346.

[19] ASTM file no. 29-0713.

[20] D. Briggs, J.C. Rivière, in: D. Briggs, M.P. Seah (Eds.), Practical Surface Analysis 1: Auger and X-ray Photoelectron Spectroscopy, 2nd ed., John Wiley and Sons, Chichester, 1990, p. 85.

[21] J. Mulder, Handbook of X-ray Photoelectron Spectroscopy, Perkin Elmer Edtr, 1982,, p. 147.

[22] L. Constant, C. Speisser, F. Le Normand, Surf. Sci. 387 (1997) 28.

[23] C.S. Cojocaru, F. Le Normand, unpublished results. 